2

UCRL-JC-112765

PREPRINT

\title{
Structural Analysis of a Superconducting Central Solenoid for the Tokamak Physics Experiment
}

\author{
Thomas G. O'Connor \\ Joseph R. Heim
}

This paper was prepared for submittal to the Thirteenth International Conference on Magnet Technology Victoria, British Columbia, Canada

September 20-24, 1993

September 15, 1993

This is a preprint of a paper intended for publication in a journal or proceedings. Since

- changes may be made before publication, this preprint is made available with the understanding that it will not be cited or reproduced without the permission of the author. 


\section{DISCLAIMER}

This document was prepared as an account of work sponsored by an agency of the United States Government. Neither the United States Government nor the University of California nor any of their employees, makes any warranty, express or implied, or assumes any legal liability or responsibility for the accuracy, completeness, or usefulness of any information, apparatus, product, or process disclosed, or represents that its use would not infringe privately owned rights. Reference herein to any specific commercial products, process, or service by trade name, trademark, manufacturer, or otherwise, does not necessarily constitute or imply its endorsement, recommendation, or favoring by the United States Govemment or the University of California. The views and opinions of authors expressed herein do not necessarily state or reflect those of the United States Government or the University of California, and shall not be used for advertising or product endorsement purposes. 


\section{Structural Analysis Of A Superconducting Central Solenoid For The Tokamak Physics Experiment}

Thomas G. O'Connor, Joseph R. Heim

Lawrence Livermore National Laboratory, Livermore, CA, USA

\begin{abstract}
The Tokamak Physics Experiment (IPX) concept design uses superconducting coils to accomplish magnetic conlinement. The central solenoid (CS) magnet is divided vertical into 8 equal segments which are powered independently. The eddy current heating from the pulsed operation is too high for a case type construction; therefore, a "no case" design has been chosen. This "no case" design uses the conductor conduit as the primary structure and the electrical insulation as a structural adhesive. This electrical insulation is the "weak link" in the coll winding pack structure and needs to be modeled in detail. A global finite element model with smeared winding pack properties was used to study the CS magnet atructural behaviot. The structural analysis results and peak stresses will be presented.
\end{abstract}

\section{INTRODUCITON}

The structural analysis of the Tokamak Physics Experiment (TPX') Central Solenoid (CS) (sec Fig. 1) includes analysis of the support structure as well as the winding pack structure. The winding pack consists of cable-in-conduit conductor wrapped with a glass wrap insulation and separated by a polyimide shecl. The entire winding pack is wrapped with ground plane insulation. In order to simplify the analysis of the central solenoid, the complex winding pack structure is approximated as an orthotropic matcrial or "smeared" mechanical propertics. The "smeared" mechanical properties were calculated from a finite element model of the conduit and insulation [1].

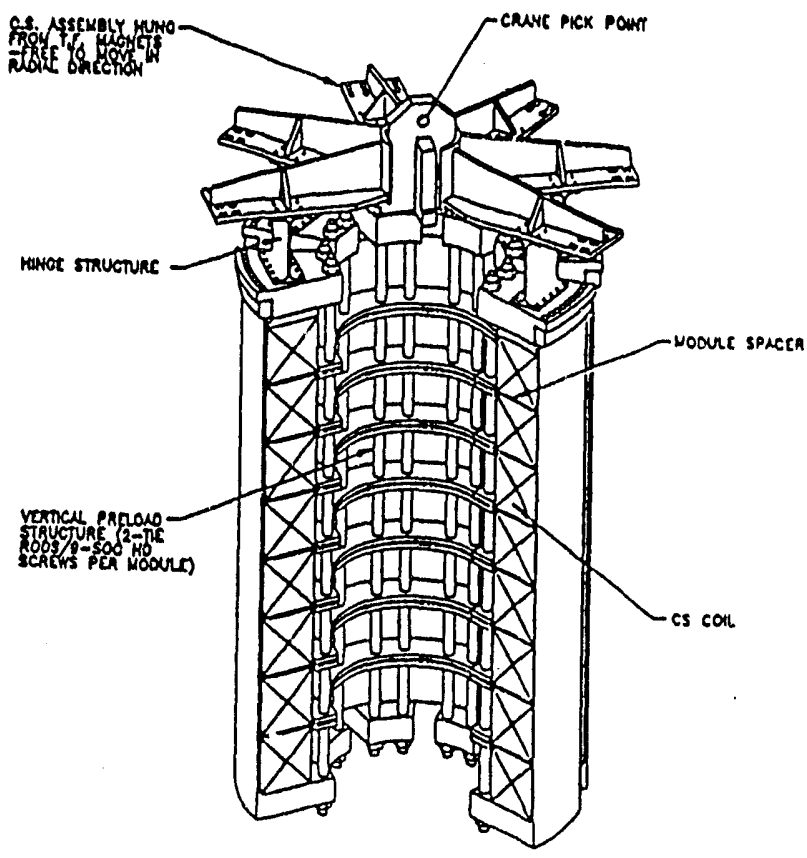

Fig. 1 Central solenoid assembly.
The finite element method was chosen for this analysis becausc the availability of commercial computer codes for simulation of magnetics, thermal, and stress problems. The analysis was carried out with ANSYS [2] , a finite clement analysis code. First, a magnetic analysis was completed to determine the Lorent forces which were then used in the stress analysis.

\section{MODEL DI:VIELOPMENT}

The central solenoid in TPX consists of 8 superconducting coil modules which are slacked vertically. The coil modules are wrapped in nominal $1 / 4$ inch ground wrap insulation (glass and polyimide material) and scparated by a $3 / 8$ inch thick stcel plate. The coils are held together by stainless stecl tic rods on the inside diameter and plates on the outside diameter, sec Fig. 1. The bolts and platc structure act as a pre-load structure, making sure the coils remain in compression during cool-down and operation. The top and bottom end caps are segmented to reduce cddy currents and are thick enough to act as rigid blocks. The I-beam hangers between the spider support and the top end caps have three functions: 1) to allow radial displacement of the top end of the coil, 2) to allow rotation of the top end of the coil, and 3) to support the coil stack-up dead weight. The main purpose of these hangers is to allow the coil to displace and rotate without generating bending stress in the coil near the top end cap, i.e. to approach a free end.

The 2-D axisymmetric model developed to analyze the central solenoid is shown in Fig. 2. The top end which is allowed to translate and rotate can be approximated as a free end. The bollom end is also a free end allowing top and bottom symmetry to be used. The model is uscd to estimate the stresses in the conduit, insulation, and support structure during cool-down and throughout the normal opcration of the central solenoid. The difference in the thermal contraction between the Incoloy conduit and Stainless Stcel support structure result in a pre-load on the winding pack. The analysis is done first without any pre-load or cool-down step to determine the stresses in the conduit and insulation which result from the Lorentz loading only. The model includes the winding pack which is represented with directional orthotropic material propertics, the polyimide ground-plane insulation around the winding packs, and the $316 \mathrm{LN}$ stainless stee! spacers between adjacent winding packs. In addition, the $316 \mathrm{LN}$ stainless stecl pre-load support structure and the end caps are included in the model.

$$
\text { encrion }
$$




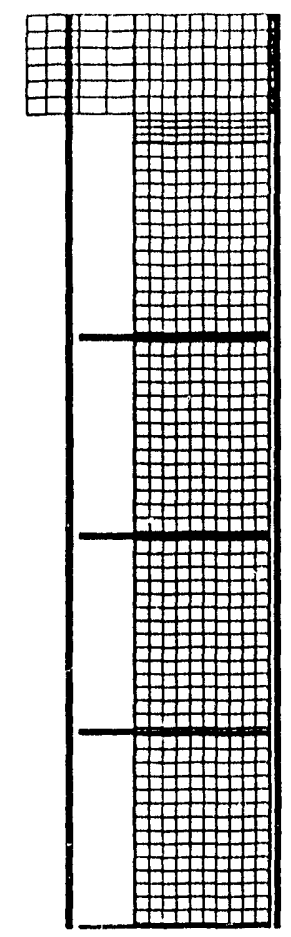

Fig. 2. 2-1) axisymmetric mesh of the central solenoid.

The central solenoid is loaded through three mechanisms, thermally - during cool down, mechanically through pre-load and magnetically - through Lorentz body forces. The central solcnoid is cooled from room temperature down to $4 \mathrm{~K}$, a delta of $289 \mathrm{~K}$, and then remains at $4 \mathrm{~K}$ for months at a time. The pre-load is applied to insure that the coils remain in compression, more specifically, that the conductor insulation will never be in tension perpendicular to the lay of the cloth. The Lorent\% forces are calculated from a magnetics model which includes all of the PF coils and the plasma. The PF coil geometry and coil currents are inputs into the magnetic model[3]. The pre-load structure pretension is obtained in the model by defining a level of pre-strain $(\mathrm{mm})$ to the ends of the tie-rods and support plates.

\section{RI:SUI.TS}

The Lorenti forces calculated in the magnetic analysis are shown in Fig. 3 for 5 timc steps (Prcbias, Start of Flattop SOF, Start of Burn SOB. End of Burn EOB, and End of Flattop EOF) corresponding to one machine cycle. The radial Lorentz burst force in the coils result in a hoop tension in the conduit. The vertical Lorenty forces sum down the length of the coil and are maximum at the midplane of the coil (PF 1). A plot of vertical force as a function of time is show in Fig. 4. PF 1 is at the center of the CS coil and PF 4 is located at the top. At $t=5.0$ (Prebias) there is a net downward vertical force of $6.6 \mathrm{MN}$ which will causes a horizontal gap to form between PF 4 and the support structure. At $l=9.0$ (SOF) there is a net upward vertical force of $3.9 \mathrm{MN}$ in PF 4 and a net

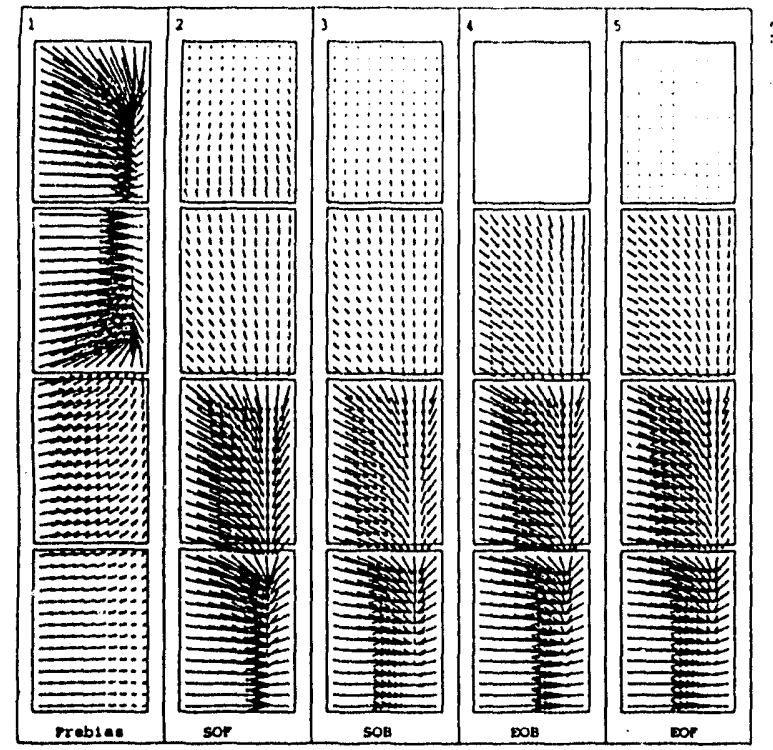

Fig. 3. Lorentz forces in the CS winding pack.

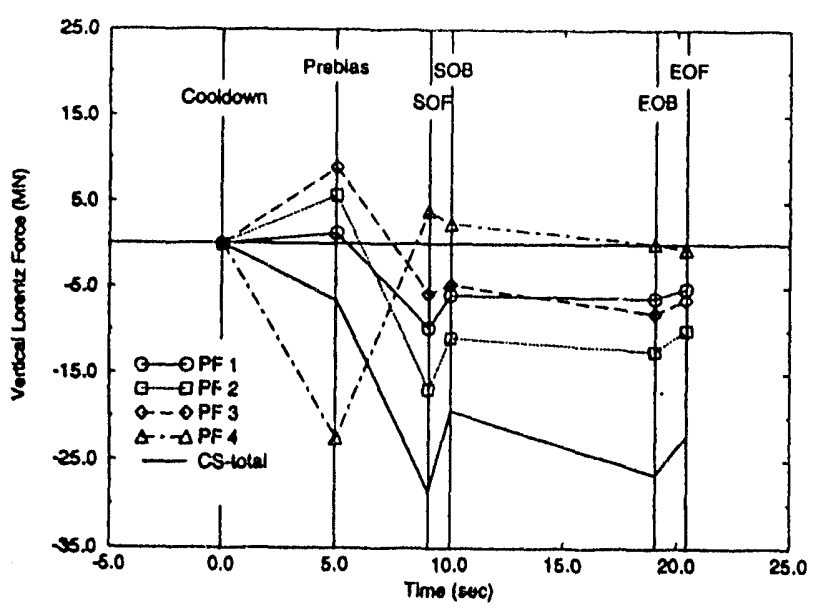

Fig. 4. Vertical L.orenty force in PF 1.4 coils during one machine cycle

downward force of $24.7 \mathrm{MN}$ in PF 1.3 which will cause a horizontal gap to from between PF 3 and PF 4. The weight of the PF 4 coil is $0.02 \mathrm{MN}$ which is 200 times smaller then the vertical upward force and does little to resist the gap formation. A pre-load is applied to the CS coils to eliminate the formation of a gaps during normal operation. In addition the pre-load is used to compress the coils and spacers together after assembly of the CS to eliminate any gaps resulting from manufacturing tolerances. A pre-load of 6.7 $\mathrm{MN}$ is obtained during cool-down from the difference in thermal contraction between the Incoloy conduit and the Stainless Stcel support structure. Additional pre-load must be applicd at room temperature to climinatc any assembly tolerance gaps between the coils and the spacers creating an integrated structure. However an increase in the pre-load also increases the vertical stress in the conduit and in turn increases its Tresca stress. The pre-load must be determirad so as not to over-stress the conduit. The maximum pre-load allowed was determined 
by (wo criteria: 1) the Tresca stress must be less then the static stress allowable for Incoloy $\left(\sigma_{\text {allow }}=800 \mathrm{MPa}|4|\right)$, 2) the stress intensity range (alternating Tresca stress) must satisfy the fatigue life requirements. The stress range does not change with an increase in pre-load because the alternating stress comes from the electro-magnetic loading. The magnet system will be thermally cycled from room temperature to $4 \mathrm{~K}$ a maximum of $3(X)$ times per the general requirements document (5), therefore an increase in preload will increase the stress intensity rang, however, the stress range is generally small and does litle to effect the overall fatigue life. However, an increase in pre-load does increase the average stress and using (1) an cquivalent stress intensity range $\left(\mathrm{S}_{\mathrm{eq}}\right)$ can be estimated to include this effect [5].

$$
S_{\mathrm{cq}}=\frac{S_{\mathrm{alt}}}{1-S_{\text {mean }} / S_{\mathrm{u}}}
$$

Where $S_{a l t}$ is the alternating stress, $S_{\text {mean }}$ is the average stress, and $S_{U}$ is the tensile strength. Fig. 5 shows that the pre-load docs increase the suress intensity range. The basc metal and weld metal allowables were cstimated from the Tresca versus Time plot shown in Fig. (6 assuming one stress amplitude (neglecting the smaller stress deviations) and the fatigue life data presented in A. Nyilas et al. [6]. A pre-load greater then $35 \mathrm{MN}$ will put the stress intensity range over the weld allowable, however, for the present load scenario a pre-load of $25 \mathrm{MN}$ results in a Tresca stress of $790 \mathrm{MPa}$ which is very close to the static allowable of $800 \mathrm{MPa}$. Depending on the load case either of the static allowable or the fatigue allowable will be the limiting one in determining the pre-load.

Fatigue crack growth is controlled primarily by the maximum principle stresses. The vertical stress duc to Lorentz forces and pre-load are in compression resulting in no crack growth. The hoop stress is in tension and is the main concern for fatigue crack growth. In Fig. 7 the hoop stress for each coil in the CS is plotted throughout one machine cycle including a cool-down cycle. Over the life

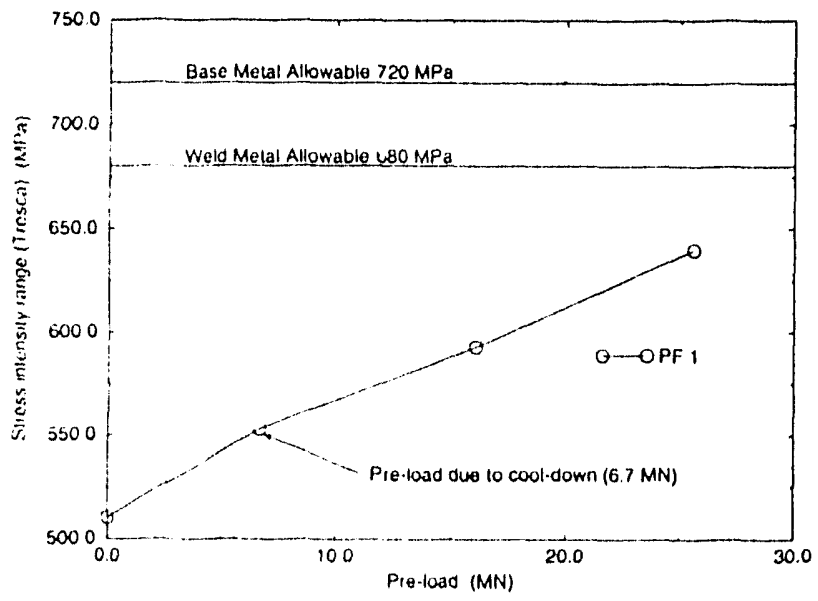

Fig. 5. Pre-load versus stress instensity range $\left(S_{e q}\right)$ in the Pli I coil

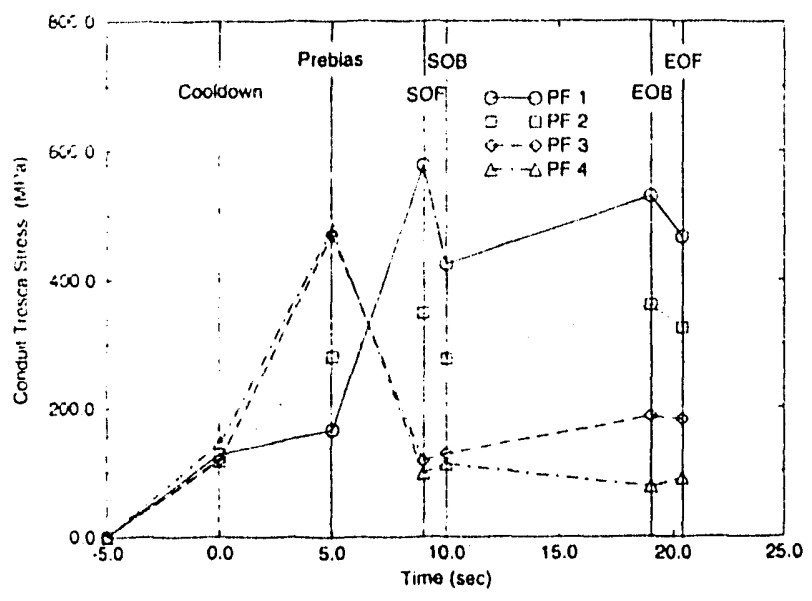

Fig. 0. Trusca stress in PI 1.4 coils during one machine cycle, includes a $6.7 \mathrm{MN}$ pre-kad obtained during cool-down

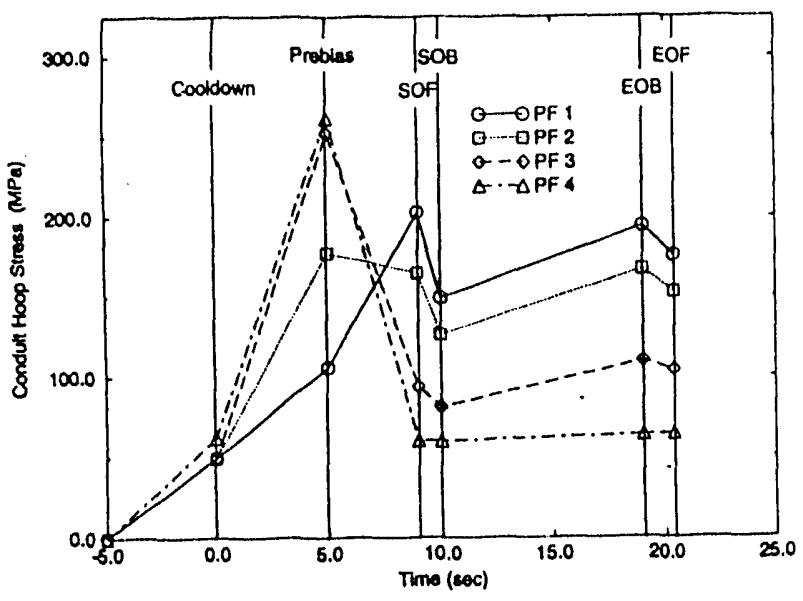

liig. 7. Conduit lloop stress in $1 \%: 1-4$ during one machine cycle, including cool-down (2.4 times the winding pack stress)

of the tokamak the CS magnet system is required to cycle through 30,000 machine cycles and 300 hot-cold cycles [5]. Using the reguirements in TPX Structural and Cryogenic Design Criteria Document 17] where the maximum permissible inilial flaw size shall be governed by, as a minimum, two times the growth life experimentally determined based on component tests, or four times the growth life detcrmined based on matcrial tests. An initial flaw size of $5 \%$ of the thickness of the conduit $(2.41 \mathrm{~mm})$ can be detected using an ultrasonic non-destructive test [8]. Base matcrial propertics can be used instead of weld matcrial properties because the conduit in the CS can mamulactured in lengths long enough that butt welds are not required. The maximum stress range is $210 \mathrm{MPa}$ in PF 4. Using the 5\% flaw size and the fatigue crack growth curves presented in R. Hoard el al. 191 for base metals a fatigue crack growth life of $2 \times 10^{6}$ can be determined. This easily satisfies the requirememt that the fatigue crack growth life be lour limes the required life. The small deviations in the stress range experienced during cool-down and throughout 
one machine ejele have little effect on the overall life of the machine for the present load case. Under the present load conditions the faligue crack growth stress range allowable is 400 to $425 \mathrm{MPa}$.

\section{ConCl.usions}

- A pre-load is necessary to climinate the formation of gaps and ultimately keep the insulation in compression throughout the life of the CS magnet.

- A portion of the pre-load is oblained during cool-down from the difference in thermal contraction between Incoloy 908 and 316LN stainless stcel.

- A maximum pre-load of $25 \mathrm{MN}$ may be applicd to the CS.

- The conductor performs adequately as the primary structure based on fatigue life and fatigue crack growth criteria.

\section{R IIIIIRI:NCIIS}

[1] T.G. O'Connor, "Smeared mechanical properties of the TPX central solenoid, LLNL, 14-930324-LLNL.TO'Connor-01, ASG-93-5.4-37, March 24, 1993

[2] ANSYS Revision 5.0, Swansion Analysis Sy'stem, Inc. Houston, PA

[3] J. Schultz, "Memo - High Current Scenario," MIT, Feb 9, 1993

(4) ITER Magnet System, ITER Magnet System Design Unit, Document Series No. 26, International Atonic Energy' Agency, Vienna, 1990.

15] W. Reiersen, ed., "TPX general requirements document", PPPL, March 15, 1993

[6] A. Nyilas, J. Zhang, B. Obst, and A. Ulbricht, "Fatigue and fatigue crack growth properties of 316LN and Incoloy 908 bclow 10K," Adv. in Cryo. Engr. Mat., vol. 38 , F.R. Fickett and R.P. Reed, Eds. New York, 1992

(7) P. Heitzenroeder, ed., "TP'X structural and cryogenic design criteria", PPPL, April 23, 1992

[8] G. Thomas and S. Benson, "Nondestructive evaluation of Incoloy 908 superconductor sheath material", unpublished

[9] R.W. Hoard and D.W. Stevens, " $\wedge$ comparison of the fatigue properties of Incoloy 908 and $316 \mathrm{LN}$ allows", LLNL, 13930326-LLNL-Hoard/Stevens-01, ASC-93-5.1-93, March 26, 1993

This work was performed under the auspices of the U.S. Department of Energy by Lawrence Livermore National Laboratory under contract No. W-7405-Eng-48. 

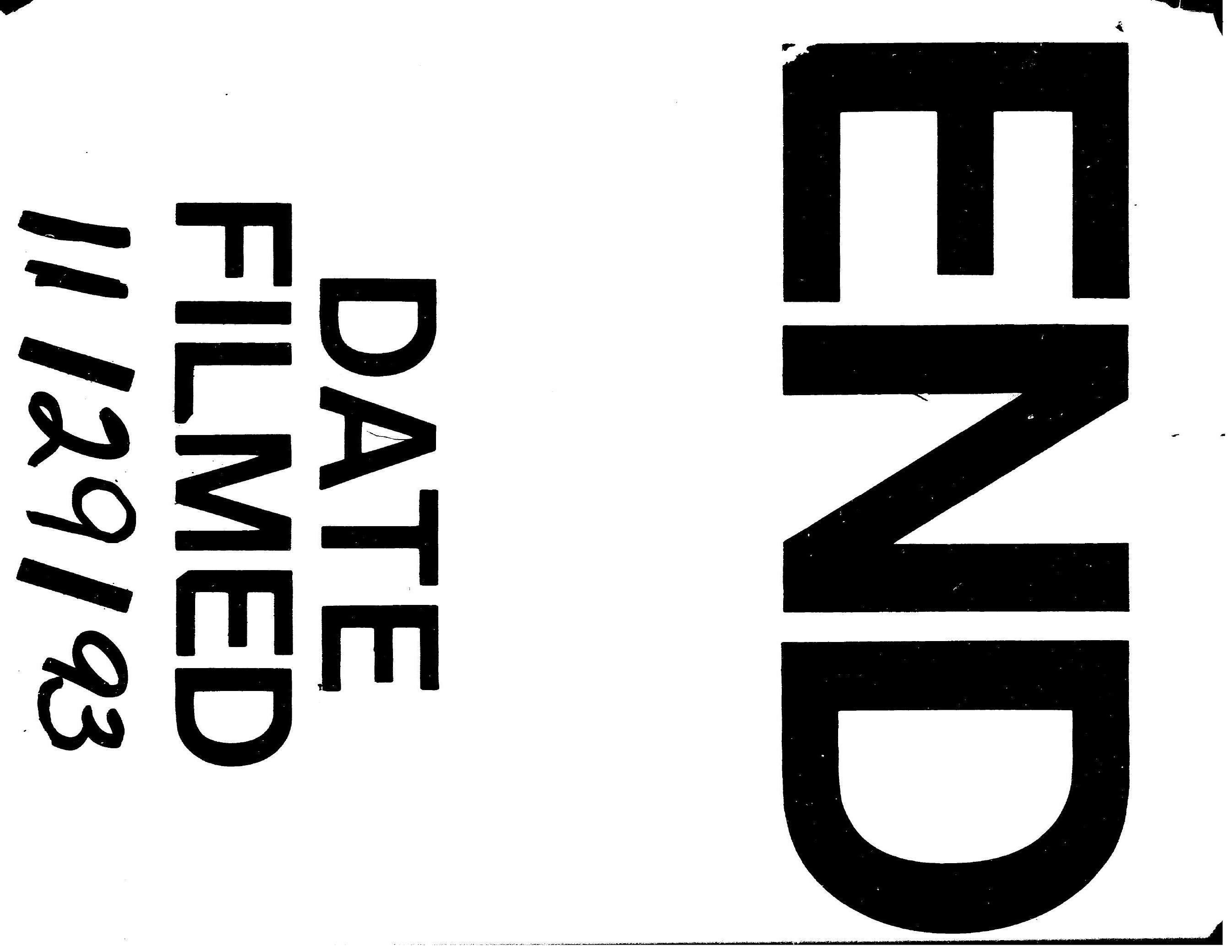
